\title{
EDUCAÇÃO DE JOVENS E ADULTOS: UMA MODALIDADE EM BUSCA DE IDENTIDADE
}

\author{
Rosângela das Neves Leite ${ }^{1}$
}

RESUMO: Protagonistas de histórias reais e ricos em experiências vividas, os alunos da EJA configuram tipos humanos e diversos, são pessoas que chegam à escola já depois de adultos formando assim grupos diversos onde cada um tem sua própria personalidade. Nessa modalidade de ensino, é fundamental que professores se preocupem em conhecer a história de vida de seus alunos, seus anseios, sua cultura, seu repertório linguístico, buscando um processo de ensino-aprendizagem que seja respeitoso e, ao mesmo tempo, produtivo. Muitos docentes da Educação de Jovens e Adultos (EJA) desconhecem a realidade de vida dos seus alunos e isso dificulta sensivelmente a interação professor-aluno e o processo ensino-aprendizagem. Conhecer o alunado da EJA é condição para que se minimize a possibilidade de ver, mais uma vez, o desânimo, a baixa autoestima, a insegurança e consequentemente a evasão escolar. Cada pessoa vai se construindo pouco a pouco todos os dias. A nossa identidade pessoal é como uma colcha de retalhos que vamos construindo através dos sentimentos, percepções e representações que temos de nós mesmos e do ambiente em que vivemos. Assim, um ensino diferenciado, respeitando a identidade e o tempo de cada indivíduo se faz necessário para a garantia de um ensino mais humanitário e significativo.

Palavras-chave: Identidade. Educação de Jovens e Adultos. Vivências. Aprendizagem.

ABSTRACT: Protagonists of real stories and rich in lived experiences, EJA students configure diverse and human types, they are people who arrive at school after adults, thus forming diverse groups where each one has its own personality. In this type of teaching, it is essential that teachers are concerned with knowing the life story of their students, their expectations, their culture, their linguistic repertoire, seeking a teaching-learning process that is respectful and, at the same time, productive. Many teachers of Youth and Adult Education (EJA) are unaware of the reality of their students' lives and this significantly hinders the teacher-student interaction and the teaching-learning process. Getting to know EJA students is a condition to minimize the possibility of seeing, once again, discouragement, low self-esteem, insecurity and, consequently, school dropout. Each person builds up little by little every day. Our personal identity is like a patchwork that

'Graduada em Pedagogia pela Faculdade Norte do Paraná (UNOPAR), Graduada em Ciências Naturais (FACIBA), ( Pós-Graduada em Educação de Jovens e Adultos (GAMA FILHO), Pós - Graduada em Gestão Escolar (GAMA FILHO). Estudante do curso de Mestrado (INTEGRALIZE). Atua como docente da rede municipal de Esplanada e Entre - Rios, cidade do estado da Bahia. Email: rleite792@gmail.com 
we build through the feelings, perceptions and representations we have of ourselves and the environment in which we live. Thus, a differentiated education, respecting the identity and time of each individual is necessary to guarantee a more humanitarian and meaningful education.

Keywords: Identity. Youth and Adult Education. Experiences. Learning.

\section{INTRODUÇÃO}

EJA é a sigla de Educação de Jovens e Adultos, uma modalidade de ensino destinada ao público que não completou, abandonou ou não teve acesso à educação formal na idade apropriada. A EJA é popularmente conhecida como supletivo. A Educação para Jovens e Adultos (EJA) é uma forma de ensino da rede pública no Brasil, com o objetivo de desenvolver o ensino fundamental e médio com qualidade, para as pessoas que não possuem idade escolar e oportunidade.

A educação de jovens e adultos (EJA) é um campo que engloba práticas, estudos e pesquisas, legislação e formação. Desde 1949, a Unesco vem realizando a cada década a Conferência Internacional de Educação de Adultos (CONFINTEA), que nos permite conhecer como se dão as diversas práticas educativas, do formal ao não formal, em diferentes partes do mundo.

Entendemos por EJA um processo de formação das pessoas ao longo da vida. Esse processo de formação sempre existiu. Mesmo antes das ações do poder público, grupos dos mais diversos como de igreja, de bairro, de associação, de sindicato, se reuniam e continuam a se reunir para dar prosseguimento a formação àqueles que, por várias razões, tiveram seus estudos interrompidos.

Com a pressão pelo atendimento ao direito a educação, conseguiu-se no Brasil imprimir na Constituição de 1988, no artigo 205, a educação como direito de todos. Para se estabelecer esse direito de todos de modo mais efetivo, Lei de Diretrizes e Bases da Educação (LDB), Lei de n. 9394/96, trouxe nos seus artigos 37 e 38 a descrição do que se entende por educação de jovens e adultos quanto a escolarização. É importante que se entenda que essa nova conceituação distingue em número e grau da antiga nomenclatura de ensino supletivo, descrita na legislação anterior da Lei n. 5692/71. Além do conceito 
de educação incluir o de ensino, aquele tem uma dimensão bem mais ampla contemplando os processos de aprendizagem e de formação dos sujeitos.

Percebemos então que a Educação de jovens e adultos se encontra, de certa forma, anestesiada devido as grandes agressões sofridas, ocasionando um choque em sua identidade. Para que se possa recuperá-la, de alguma forma, é necessário que se realize uma contraposição com as três instâncias do atual sistema de ensino. São elas:

- Dimensão política, que vai muito além da escola, está presente em todo o sistema educativo e é regida pelo órgão máximo como esferas de governos e secretarias de educação;

- Dimensão Gerencial, que é mais ligada a gestão da educação e não compreende, ao que entendo, somente ao sistema político, mas também a gestão do ambiente educativo em particular;

- Dimensão pedagógica, entende-se que é a principal, por se tratar da sala de aula, ambiente mais específico, compreendendo exclusivamente o professor como autoridade máxima dentro de sala de aula, capaz de nortear seus alunos para seguir em frente. É a dimensão mais peculiar, por se tratar do ato pedagógico compreendendo sempre os alunos e o professor.

$\mathrm{Na}$ atuação pedagógica deve ser acrescentada a dimensão educativa, que lhe é imputada por força de sua própria definição institucional. $O$ professor é um educador... e, não querendo sê-lo, torna-se um deseducador. " (GADOTTI, ROMAO, 2011:7I)

\section{A EJA E SUA IDENTIDADE}

Construir uma identidade, para Erikson (1972), implica em definir quem a pessoa é, quais são seus valores e quais as direções que deseja seguir pela vida. O autor entende que identidade é uma concepção de si mesmo, composta de valores, crenças e metas com os quais o indivíduo está solidamente comprometido. A formação da identidade recebe a influência de fatores intrapessoais (as capacidades inatas do indivíduo e as características adquiridas da personalidade), de fatores interpessoais (identificações com outras pessoas) e de fatores culturais (valores sociais que uma pessoa está exposta, tanto global quanto 
comunitários). Este sentimento de ter uma identidade pessoal dá-se de duas formas: a primeira é perceber-se como sendo o mesmo e contínuo no tempo e no espaço; e a segunda é perceber que os outros reconhecem essa semelhança e continuidade.

Kimmel e Weiner (1998) afirmam que, quanto mais desenvolvido o sentimento de identidade, mais o indivíduo valoriza o modo em que é parecido ou diferente dos demais e mais claramente reconhece suas limitações e habilidades. Quanto menos desenvolvida está a identidade, mais o indivíduo necessita de apoio, de opiniões externas para avaliar-se e compreender menos as pessoas como distintas.

Cada pessoa vai se construindo pouco a pouco todos os dias. A nossa identidade pessoal é como uma colcha de retalhos que vamos construindo através dos sentimentos, percepções e representações que temos de nós mesmos e do ambiente em que vivemos. Protagonistas de histórias reais e ricos em experiências vividas, os alunos da EJA configuram tipos humanos e diversos, são pessoas que chegam à escola já depois de adultos formando assim grupos diversos onde cada um tem sua própria personalidade.

\section{${ }_{3}$ OS SUJEITOS ENVOLVIDOS NA EDUCAÇÃO DE JOVENS E ADULTOS}

A EJA é uma prática escolar e social que envolve estudantes, professores, coordenadores de escola e gestores públicos. Como se trata de um público "desconhecido" de nossos cursos de licenciaturas, há a necessidade de uma preparação mínima para se trabalhar na EJA. Como afirma Miguel Arroyo (2012), "se são outros sujeitos, requerem outras pedagogias”. Cada vez mais os desafios colocados pela EJA requerem essa preparação. Há de superar a falta de critério utilizada por equipes de secretarias que simplesmente "alocam" docentes na EJA. Em algumas regiões metropolitanas, existem centros especialmente destinados aos jovens e adultos que adotam formas de organização do ensino flexíveis e inovadoras (Haddad et al, 2007), porém a oferta pública de EJA quase sempre é realizada em período noturno e nas mesmas escolas - e com os mesmos professores - que atendem em período diurno crianças e adolescentes. Como a maioria das licenciaturas não prepara para atuar com jovens e adultos, os professores tendem a reproduzir nessas turmas os métodos e conteúdos curriculares do ensino das crianças, até que o acúmulo de experiência e o trabalho coletivo lhes permita construir novos saberes da 
docência (Pereira e Fonseca, 20or; Ribeiro, 1999). A rotatividade dos professores, que na maior parte dos casos apenas completa suas jornadas de trabalho na EJA, entretanto, torna os esforços de formação em serviço pouco efetivos. O coordenador desempenha um papel estratégico para o enfrentamento desse quadro, pois cabe a ele promover a formação continuada da equipe e incentivar o estudo, as práticas de registro, a análise crítica e o intercâmbio de experiências.

Quando procuramos pela identidade pedagógica dos cursos de EJA, na maior parte dos casos, nos deparamos com algo muito assemelhado ao antigo Ensino Supletivo: cursos acelerados voltados à reposição dos mesmos conteúdos escolares veiculados no ensino infanto-juvenil. O currículo tende a ser pouco significativo e desconectado das necessidades de aprendizagem dos jovens e adultos. Além do risco de infantilização dos estudantes, essa abordagem compensatória ignora a riqueza de saberes das pessoas jovens e adultas, tendendo a vê-las como indivíduos aos quais faltam conhecimentos. A questão que se coloca, então, é como tornar o ensino básico para os jovens e adultos mais relevante e atrativo, de modo a reverter a baixa procura, os elevados índices de abandono e o desprestígio da modalidade.

\section{CONSIDERAÇÕES FINAIS}

$\mathrm{O}$ avanço conquistado pelo campo da educação de jovens e adultos colocou a EJA em outro patamar em que já não é possível mais conviver com a improvisação, isto é, sua prática exige ações mais permanentes. É preciso superar o voluntarismo, incentivando a formação e uma melhor preparação do educador de jovens e adultos. Haver um coordenador que conheça a realidade do público da EJA é fundamental para realizar a mediação entre estudantes e professores e garantir um acolhimento com base na escuta atenta, tão necessária a quem volta a estudar depois de muito tempo. Uma característica comum a EJA é o fato de ela atender a uma diversidade de sujeitos. A EJA é por si heterogênea: encontramos adolescentes, jovens, adultos e idosos.

Considerando as realidades sociais em nosso país, a desigualdade racial, econômica e de gênero aparece também no perfil das turmas de Educação de Jovens e Adultos (EJA), majoritariamente compostas por pessoas negras e trabalhadoras. Nesse sentido, a EJA 
apresenta especificidades, problemáticas e metodologias próprias que não só devem ser visibilizadas, como também podem inspirar práticas pedagógicas e estratégias de gestão em todo o sistema de ensino, sobretudo no atual contexto de crise econômica e sanitária. Parte dessa construção envolve o reconhecimento dos saberes próprios dos estudantes dessa modalidade, enquanto sujeitos da sua aprendizagem, cujos conhecimentos devem ser valorizados pelo currículo. Reconhecer e valorizar as trajetórias, saberes e fazeres diversos de jovens e adultos contribui para a formação de competências scio emocionais, fortalecendo práticas pedagógicas dialógicas e democráticas. A EJA apresenta possibilidades que não se limitam às especificidades da sua modalidade, podendo inspirar estratégias de ensino em toda a educação.

Protagonistas de histórias reais e ricos em experiências vividas, os alunos da EJA configuram tipos humanos e diversos, são pessoas que chegam à escola já depois de adultos formando assim grupos diversos onde cada um tem sua própria personalidade.

\section{REFERÊNCIAS}

ARROYO, Miguel. Outros Sujeitos, Outras Pedagogias. Petrópolis, RJ: Vozes, 2012.

Passageiros da Noite. 2017

BRASIL. MEC. Lei de Diretrizes e Bases da Educação. Disponível em: 〈http://www.mec.gov.br>. Acesso em: I2 de abril de 2010.

. Plano Nacional de Educação. Disponível em: 〈http://www.mec.gov.br〉. Acesso em: 12 de abril de 2010.

- Lei de Diretrizes e Bases da Educação no 5692 de Ir.08.71, capítulo IV. Ensino Supletivo. Legislação do Ensino Supletivo, MEC, DFU, Departamento de Documentação e Divulgação, Brasília, 1974 .

PARECER no 699/7r. Regulamenta o capítulo IV da Lei 5.692/71. o6 de julho de 1972. Constituição Federal de Educação. Rio de Janeiro.

Secretaria de Educação Fundamental. Parâmetros Curriculares Nacionais: Terceiro e quarto ciclos; Apresentação dos temas transversais. Brasília: MEC /SEF, I998, [Versão disponibilizada na internet pelo Sindicato das Escolas Particulares de Santa Catarina (Sinepe/SC):www.sinepe-sc.org.br/sa8tt.html].

DEMO, Pedro. Metodologia do conhecimento centífico. São Paulo: Atlas, 2000. 
DI PIERRO, M. C.; VOVIO, C. L.; ANDRADE, E. R. Alfabetização de Jovens e Adultos: Lições da Prática. Brasília: Unesco, 2008.

ERIKSON, E. H. (1972). Identidade, juventude e crise Rio de Janeiro, RJ: Zahar.

FREIRE, Paulo. Educação de Adultos, algumas reflexões. In. GADOTTI, Moacir; ROMÂO, José E. (Orgs.) Educação de jovens e adultos: teoria, prática e proposta. 6 ed. São Paulo: Cortez, 2003.

GADOTTI, Moacir; ROMÃO, José. (org.). Educação de jovens e adultos: teoria, prática e proposta. São Paulo. Editora Cortez, 201 I.

GALVÃO, A. M.; DI PIERRO, M. C. Preconceito contra o Analfabeto, $2^{\underline{a}}$ ed. São Paulo: Cortez, 2013 (Coleção Preconceitos, vol. 2).

HADDAD, Sérgio. Tendências atuais na educação de jovens e adultos. Em Aberto, Brasília: ano II, nº 56, out/dez. 1992.

- A educação de pessoas jovens e adultas e a nova LDB. p.io6-i22. In: BRZEZINSKI, Iria (org.). LDB interpretada: diversos olhares se entrecruzam. São Paulo: Cortez, 1997.

Novos Caminhos em Educação de Jovens e Adultos: Um Estudo de Ações do Poder Público em Cidades de Regiões Metropolitanas Brasileiras. São Paulo, Global, Ação Educativa, Fapesp, 2007.

KIMMEL, D. C., \& WEINER, I. (1998). La adolescencia: una transición del desarrollo. Barcelona: Ariel.

PEREIRA, J. E. D.; FONSECA, M. C. F. R. Identidade Docente e Formação de Educadores de Jovens e Adultos. Porto Alegre, Educação \& Realidade, vol. 6, n. 2, p. 51-73, jul./dez. 200I.

PINTO, Álvaro Vieira. Sete lições sobre educação de adultos. São Paulo. Editora Cortez, 2010.

SOARES, Leôncio. Trajetórias compartilhadas de um educador de jovens e adultos. Belo Horizonte: Autêntica, 2oI9.

As Especificidades na Formação do Educador de Jovens e Adultos: Um Estudo sobre Propostas de EJA. Educação em Revista, Belo Horizonte, v. 27, n. 2, ago. 2011. 